\title{
AVALIAÇÃO DA ACURÁCIA DO CÁLCULO DE VOLUME DE PILHAS DE REJEITO UTILIZANDO VANT, GNSS E LiDAR
}

\section{Evaluating the accuracy in volume calculation in a pile of waste using $U A V$, GNSS and LiDAR}

\author{
Cristiano Alves da Silva ${ }^{1}$ \\ Cynthia Romariz Duarte ${ }^{2}$ \\ Michael Vandesteen Silva Souto ${ }^{2}$ \\ André Luis Silva Dos Santos ${ }^{3}$ \\ Venerando Eustaquio Amaro ${ }^{4}$ \\ Cristina Prando Bicho ${ }^{1}$ \\ José Antonio Beltrão Sabadia²
}

Departamento Nacional de Produção Mineral1- DNPM. Rua Dr. José Lourenço 905 - $60115-280$ Fortaleza - CE, Brasil. Email:cristiano.silva@dnpm.gov.br;Email:cristina.bicho@dnpm.gov.br

Universidade Federal do Ceará2 - UFC. Departamento de Geologia - Bloco 912 - 60455-760 - Fortaleza - CE, Brasil.Email: cynthia.duarte@ufc.br; Email: michael.souto@ufc.br; Email: sabadia@ufc.br

Instituto Federal do Maranhão - IFMA. Av. Marechal Castelo Branco 789 - 6076-091 - São Luís - MA, Brasil. andresantos@ifma.edu.br

Universidade Federal do Rio Grande do Norte ${ }^{4}$ - UFRN. Campus Universitário - 59078-970 - Natal - RN, Brasil. venerandoamaro@gmail.com

\section{Resumo:}

Dentre as diversas tecnologias utilizadas para cálculo do volume de materiais na mineração, o Veículo Aéreo Não Tripulado (VANT) e o Light Detecting And Ranging (LiDAR), surgem como alternativas rápidas e precisas, em comparação com as técnicas de topografia tradicionais como estação total e Global Navigation Satellite System (GNSS). Diante destas novas tecnologias, este estudo avaliou a acurácia do cálculo de volume, realizado por meio de Modelos Digitais de Terreno (MDTs), gerados a partir das tecnologias VANT, LiDAR e GNSS, em uma pilha de rejeito da extração de calcário laminado, explorado para fabricação de lajotas in natura, comercializado com o nome de "Pedra Cariri", no município de Santana do Cariri, no Estado do Ceará. A avaliação da acurácia foi realizada com base no método de testes de hipóteses, a partir da análise de tendência e precisão, sendo os resultados classificados de acordo com o Padrão de Exatidão Cartográfica dos Produtos Cartográficos Digitais (PEC-PCD). Como resultado, o modelo gerado a partir do VANT apresentou a melhor acurácia no cálculo de volume da pilha de rejeito, objeto deste estudo, seguido pela modelagem obtida pelos levantamentos GNSS e LiDAR.

Palavras-chave: MDT, ARP, Bacia do Araripe, Pedra Cariri. 


\begin{abstract}
:
Among the various technologies used for calculate the volume of materials in mining, the Unmanned Aerial Vehicle (UAV) and the Light Detecting And Ranging (LiDAR), appear as fast and accurate alternatives compared to traditional surveying techniques such as total station and Global Navigation Satellite System (GNSS). Using these new technologies, the aim of this study was to evaluate the accuracy in volume calculation, performed by Digital Terrain Models (DTM), generated from the UAV technologies, LiDAR and GNSS in a pile of waste extraction laminated limestone (reject material), exploited for the manufacture of tiles in nature, marketed under the name of "Cariri Stone" in the city of Santana do Cariri, state of Ceará. The assessment of accuracy was based on hypothesis testing method, from the trend and precision of analysis, and the results classified according to the Cartographic Accuracy of Digital Cartographic Standard Products (PEC-PCD). As a result, the model generated from the UAV presented the best accuracy in the waste cell volume calculation, object of this study, followed by modeling obtained by GNSS surveys and LiDAR.
\end{abstract}

Keywords: DTM, RPA, Araripe Basin, Cariri Stone.

\title{
1. Introdução
}

De acordo com Ribeiro Júnior (2011), a determinação de volumes na mineração se faz necessária desde a fase de pesquisa, no dimensionamento de corpos mineralizados, passando pelas operações de mina, como nos desmontes e disposições de materiais, até a fase final de produção com a medição dos produtos gerados. Sendo os equipamentos topográficos como estação total e, mais recentemente, a tecnologia GNSS as técnicas mais empregadas para esta finalidade. Entretanto, nos últimos anos, tecnologias de sensoriamento remoto vêm ganhando espaço, uma vez que proporcionam resultados cada vez mais rápidos e precisos, como VANT e LiDAR, capazes de gerar Modelo Digital do Terreno (MDT) de alta acurácia, sem a necessidade direta do contato do operador com a superfície modelada.

Diante destas novas tecnologias, o objetivo deste estudo foi avaliar a acurácia da cubagem de pilhas de rejeito por meio de MDTs, elaborados a partir de levantamentos utilizando GNSS, VANT e LiDAR, em uma área localizada na Bacia do Araripe, no município de Santana do Cariri, porção sul do Estado do Ceará, próxima da Chapada do Araripe, dentro dos limites do Geoparque Araripe (Figura 1).

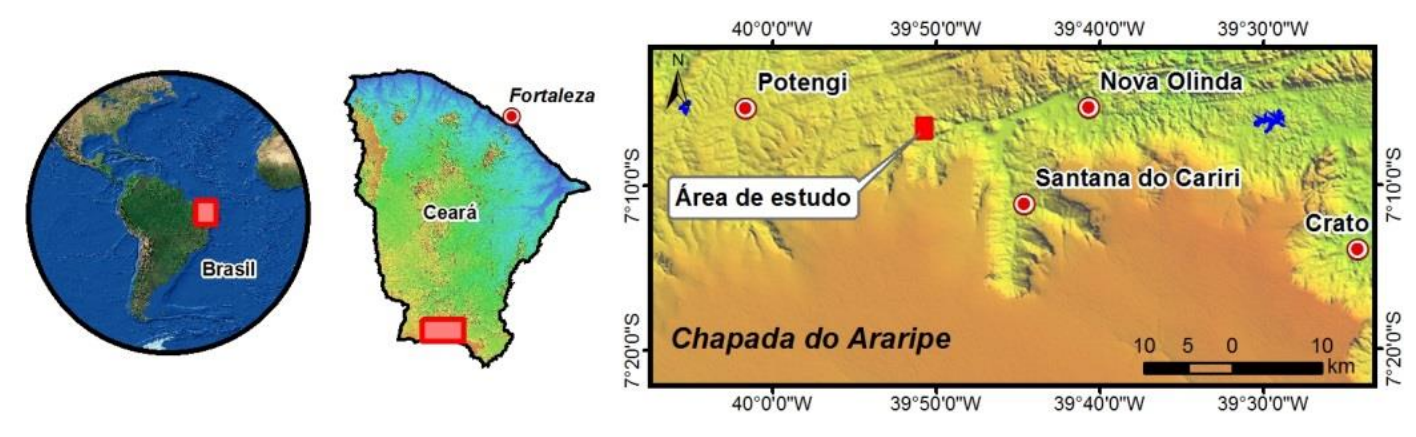

Bol. Ciênc. Geod., sec. Artigos, Curitiba, v. 22, nํ1, p.73 -94, jan-mar, 2016. 
Figura 1: Localização da área de estudo.

A área de estudo corresponde a uma grande pilha de rejeito da extração de calcário laminado, explorado para fabricação de lajotas in natura, para piso e revestimento, comercializado com o nome de "Pedra Cariri". Formada em apenas quatro anos, fato que denota a grande produção de rejeito desta atividade de mineração, esta pilha está disposta sobre a vertente de um riacho com declividade de aproximadamente $15^{\circ}$, considerando a declividade no entorno da pilha, recobrindo área de 1,38 ha com altitude variando entre 506 e $529 \mathrm{~m}$, taludes de até $28 \mathrm{~m}$ e declividade superior a $45^{\circ}$, com topo irregular (Figura 2).

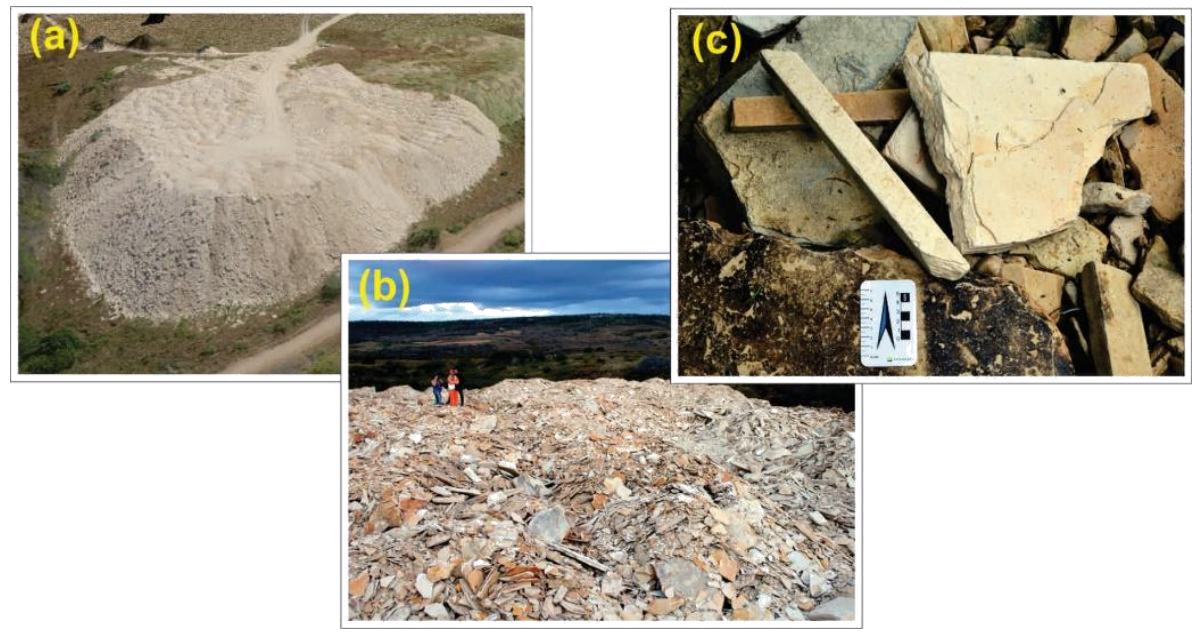

Figura 2: Pilha de rejeito da Pedra Cariri. (a) vista geral da pilha de rejeito; (b) superfície irregular do topo da pilha; (c) detalhe dos fragmentos que compõem a pilha de rejeito.

Vidal \& Castro (2009) estimam que as perdas nas diversas etapas da produção da Pedra Cariri cheguem a $70 \%$ de todo o material explotado, sendo o assoreamento dos rios e riachos locais o maior problema causado por esta grande produção de rejeito. Vidal et al. (2005) estima em mais de 1 milhão de metros cúbicos, o volume de rejeito espalhado em dezenas de pilhas localizadas nos municípios de Santana do Cariri e Nova Olinda. Elas são compostas basicamente por calcário calcítico de alta pureza $\left(54 \%\right.$ de $\mathrm{CaO}$, em média, que corresponde a $96 \%$ de $\left.\mathrm{CaCO}_{3}\right)$, denotando seu grande potencial de aproveitamento como matéria prima para fabricação de cimento, concreto, blocos cerâmicos, argamassa, etc. (Moura et al., 2013; Menezes et al., 2010; Silva, 2008).

Diante do exposto, justifica-se a necessidade de cubar estas pilhas visando seu aproveitamento econômico, bem como monitoramento, a fim de garantir a disposição adequada do material, garantido à estabilidade das pilhas e evitando problemas como assoreamento dos recursos hídricos. Portanto, neste estudo, foram empregados levantamentos de campo utilizando as tecnologias GNSS, VANT e LiDAR, realizados simultaneamente, entre os dias 9 e 10 de julho de 2014, tomando como referência pontos pré-sinalizados e georreferenciados com o uso do GNSS geodésico.

Para avaliação da acurácia foi utilizado o método de testes de hipóteses, baseado na análise de tendências e precisão do produto. Segundo Galo \& Camargo (1994), os testes específicos para esse tipo de análise são realizados por meio da detecção de tendências, baseada na distribuição $t$ de Student, identificando a existência de erros sistemáticos, e a análise de precisão baseada na distribuição Qui-quadrado, para avaliação dos efeitos dos erros aleatórios. 
De posse dos resultados da avaliação da acurácia da cubagem de pilhas de rejeito por meio de MDTs, feitos a partir de levantamentos utilizando GNSS, VANT e LiDAR, foi possível avaliar a melhor solução para o problema proposto, considerando que foram aplicadas metodologias de levantamento de campo que permitissem o melhor resultado no menor tempo possível, haja vista que a mineração estava em plena atividade e a adição de material à pilha era constante. Tal avaliação permitiu identificar a ferramenta mais adequada para auxiliar projetos de ordenamento da exploração da Pedra Cariri, buscando o desenvolvimento da região pautado no respeito à legislação vigente, subsidiando a garantia de renda e desenvolvimento para a região.

\section{Material e Métodos}

São descritos neste tópico os materiais e métodos empregados para mensurar o volume da pilha de rejeito objeto deste estudo, bem como a metodologia de avaliação da acurácia dos modelos obtidos por meio de GNSS, VANT e LiDAR, utilizando análise de tendência e precisão, sendo os resultados classificados de acordo com o Padrão de Exatidão Cartográfica dos Produtos Cartográficos Digitais (PEC-PCD).

\subsection{Global Navigation Satellite System (GNSS)}

O levantamento para o cálculo de volume da pilha de rejeito com GNSS foi realizado utilizandose um par de receptores de dupla frequência L1/L2 da marca GTR-G ${ }^{2}$, com capacidade de rastreio de satélites GPS e GLONASS. Para pós-processamento dos dados obtidos foram usados o software GNSS Solutions versão 3.10.07 e o serviço online do Instituto Brasileiro de Geografia e Estatística (IBGE), o IBGE-PPP (Posicionamento por Ponto Preciso), que processa dados GNSS e seu resultado independe de qualquer ajustamento de rede geodésica, não estando associado às realizações ou ajustamentos de rede planimétrica. Deste modo, os resultados obtidos por meio deste serviço possuem uma pequena diferença daqueles disponíveis no Banco de Dados Geodésicos (BDG). Estudos como o de Perdigão e Santos (2010), demonstram que levantamentos com tempo de rastreio superior a 2 horas, pós-processados utilizando o IBGEPPP, apresentam padrões de alta precisão, atingindo após 6 horas de rastreio precisão de $2 \mathrm{~cm}$.

Como estação de referência para os levantamentos na área de estudo, foi implantado um marco de concreto, localizado a $370 \mathrm{~m}$ da pilha de rejeito objeto deste estudo, para fornecer referencial geodésico unívoco, fixo e relativamente estável no tempo (Santos et al., 2011). Sendo as coordenadas e altitude geométrica determinadas pelo método de posicionamento relativo estático, com 8 horas de rastreio, pós-processada pelo método IBGE-PPP, obtendo como resultados, com níveis de confiança de $95 \%$, precisão horizontal de 0,01 m e 0,02 m vertical.

Para o cálculo do volume, foi gerado um MDT com base na nuvem de pontos obtida a partir do método de posicionamento relativo cinemático com taxa de ocupação de um ponto por segundo. De acordo com IBGE (2008) este método consiste em se determinar um conjunto de coordenadas para cada época de observação, onde um receptor ocupa a estação de referência enquanto o outro se desloca sobre as feições de interesse. Neste contexto, primeiramente foi 
realizado o caminhamento no perímetro inferior e superior da pilha, e posteriormente foram percorridas linhas paralelas sobre a pilha com espaçamento médio de $10 \mathrm{~m}$, gerando uma nuvem de pontos com precisão média horizontal de $0,05 \mathrm{~m}$ e vertical de $0,06 \mathrm{~m}$, com níveis de confiança de $95 \%$ (Figura 3 ).

O GNSS também foi utilizado neste estudo para georreferenciar: (1) os targets (alvos) utilizados como referência pelo LiDAR; (2) os marcos pré-sinalizados utilizados como pontos de apoio para orientação das aerofotos obtidas pelo VANT; e (3) os marcos de referência para avaliação da acurácia dos MDTs gerados pelo GNSS, VANT e LiDAR. Para as três situações foram realizados levantamentos por posicionamento relativo estático-rápido, utilizado como base um receptor de dupla frequência L1/L2 da marca GTR-G², e como rover um receptor de frequência L1 da marca South S750, com tempo de rastreio de cinco minutos, obtendo como resultados, com níveis de confiança de $95 \%$, precisão horizontal e vertical de até $0,003 \mathrm{~m}$.

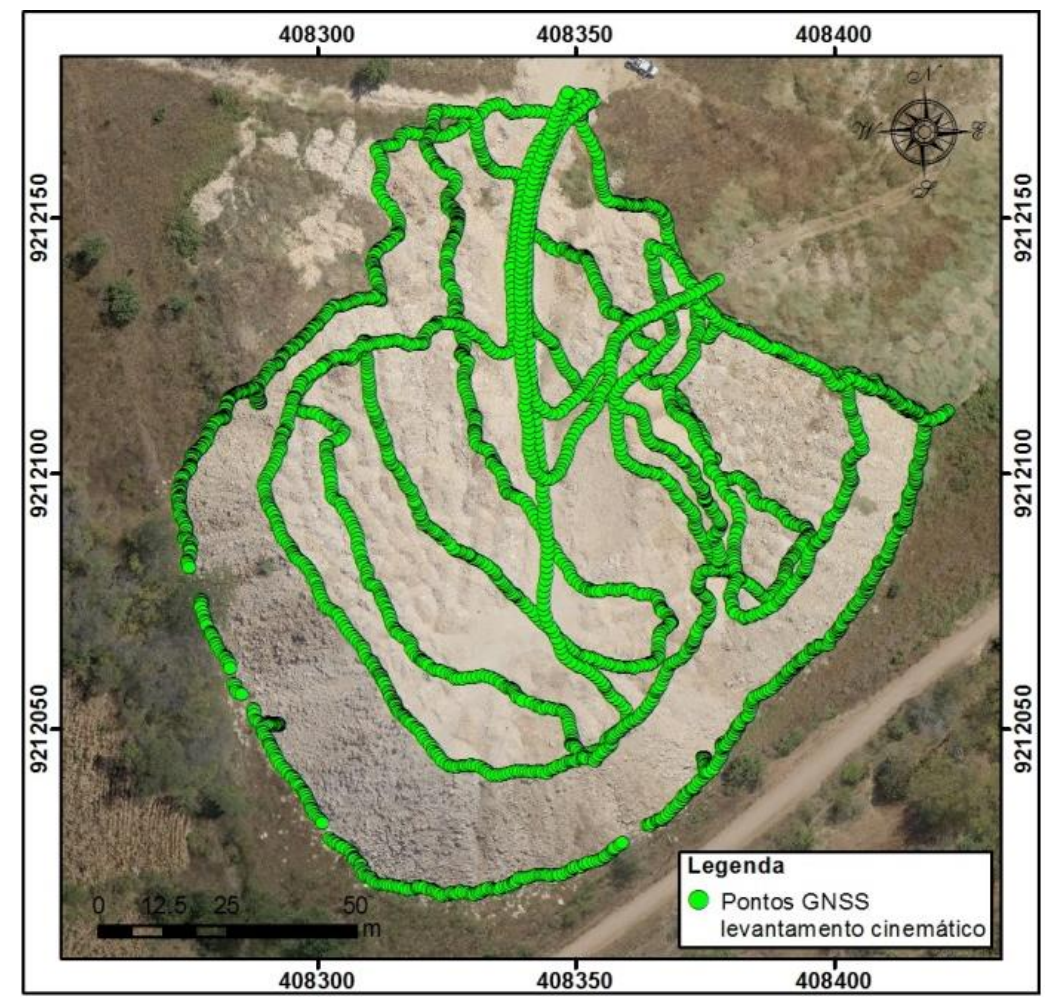

Figura 3: Levantamento realizado com GNSS para cálculo do volume da pilha de rejeito.

\subsection{VANT}

O VANT utilizado neste trabalho, ilustrado na Figura 4, foi desenvolvido pela Universidade de Brasília (UnB) em parceria com o Departamento Nacional de Produção Mineral (DNPM) e batizada como $\mu$ VANT/DNPM. Esta aeronave recebeu em 2013 da Agência Nacional de Aviação Civil (ANAC) o Certificado de Autorização de Voo Experimental (CAVE). Suas principais características são: envergadura de $1,90 \mathrm{~m}$, alcançando velocidade de cruzeiro de 60 $\mathrm{km} / \mathrm{h}$, capacidade de carga paga (payload) de $700 \mathrm{~g}$, com peso total de $2,5 \mathrm{~kg}$, possuindo motor elétrico brushless, com capacidade de operar a uma distância de até $4 \mathrm{~km}$ da base, utilizando bateria de LiPo de 4 células, 14,8 v e $5.000 \mathrm{mAh}$, com autonomia de 45 minutos de voo, tempo 
suficiente para percorrer até $20 \mathrm{~km}$ de linhas de voo, recobrindo cerca $2 \mathrm{~km}^{2}$ por voo, voando a $200 \mathrm{~m}$ de altura e com área de recobrimento lateral das fotos de $60 \%$.

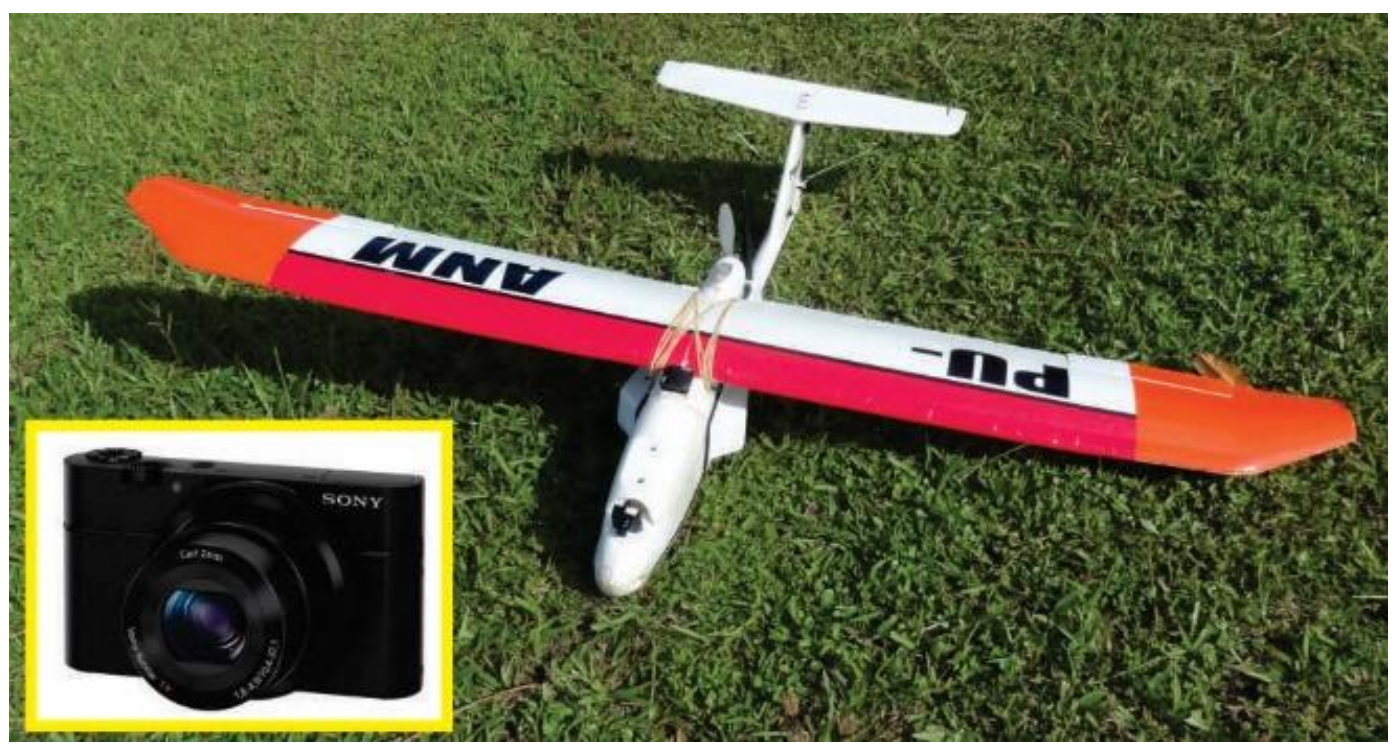

Figura 4: VANT desenvolvido pela UnB em parceria com o DNPM. No detalhe, a câmara não métrica, modelo DSC-RX100, empregada na obtenção das aerofotos.

Para captura das aerofotos o $\mu$ VANT/DNPM foi equipado com uma câmera digital de pequeno formato não métrica Sony Cyber-Shot, modelo DSC-RX100 de 20,2 megapixels (5472 x 3648 px), sensor CMOS de 13,2 x $8,8 \mathrm{~mm}$, distância focal de $10,4 \mathrm{~mm}$ e abertura f/1,8, com estabilização óptica, velocidade de obturação máxima de $0,0005 \mathrm{~s}$, pesando $213 \mathrm{~g}$ com bateria e cartão de memória.

Segundo Silva et al. (2015), a metodologia utilizada para aquisição e processamento dos dados obtidos pelo $\mu$ VANT/DNPM, está dividida em três etapas: (1) planejamento de voo; (2) execução do voo; e (3) pós-voo. Conforme ilustradas no fluxograma da Figura 5 e descritas em detalhe na sequência. 


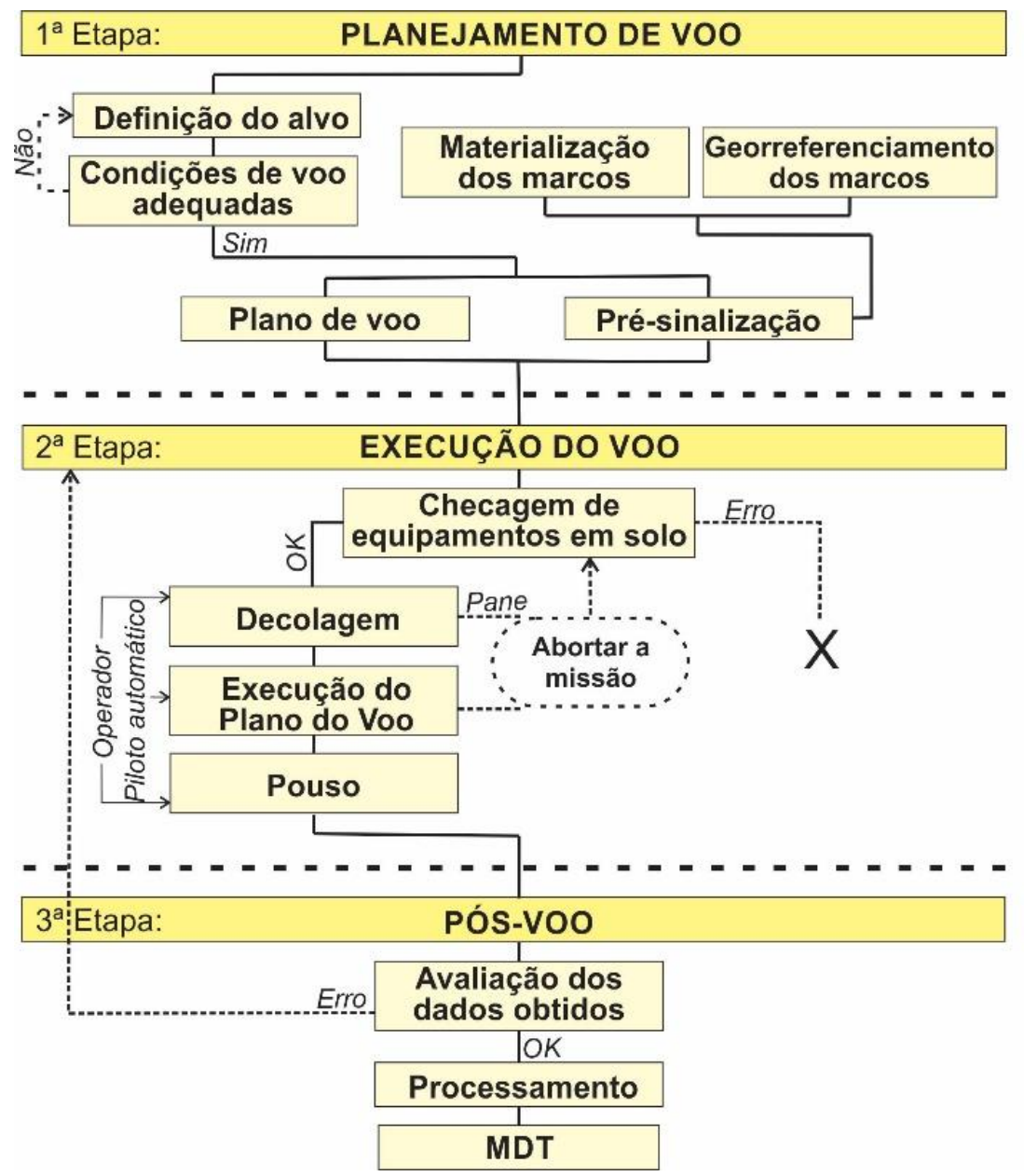

Figura 5: Fluxograma da metodologia empregada para geração de MDT utilizando o $\mu$ VANT/DNPM. Fonte: Adaptado de Silva (2014).

\section{Etapa 1: Planejamento de voo}

A etapa de planejamento de voo envolve a definição do alvo a ser sobrevoado, sendo posteriormente verificadas as condições necessárias para realização do voo, que consiste na autorização das autoridades competentes, por meio da solicitação de um NOTAM (acrônimo de "Notice to Airmen", que significa "Aviso aos Aeronavegantes") ao Departamento de Controle do Espaço Aéreo (DECEA), órgão ligado a Aeronáutica. O objetivo deste documento foi estabelecer um espaço aéreo segregado para operação do $\mu$ VANT/DNPM, ficando proibida a operação em espaço aéreo compartilhado com aeronaves tripuladas, garantindo a segurança da navegação aérea.

Com todas as condições de voo adequadas, foi realizado o plano voo, a ser executado pelo piloto automático do $\mu \mathrm{VANT/DNPM}$, e a pré-sinalização da área do sobrevoo, que consistiu em materializar em campo uma marcação artificial no terreno possível de ser identificada nas fotografias aéreas, com o objetivo de proporcionar medições mais precisas das coordenadas dos pontos de apoio necessários para orientação das aerofotos. Neste contexto, foram présinalizados, com tinta spray vermelha, 20 marcos de $50 \mathrm{x} 50 \mathrm{~cm}$ de dimensão e georreferenciados com GNSS geodésico. Do total de marcos materializados, 10 foram usados como pontos de apoio para orientação das aerofotos e 10 como pontos de referência para realizar a avaliação da acurácia dos MDTs resultantes das três modelagens realizadas (Figura 6). 


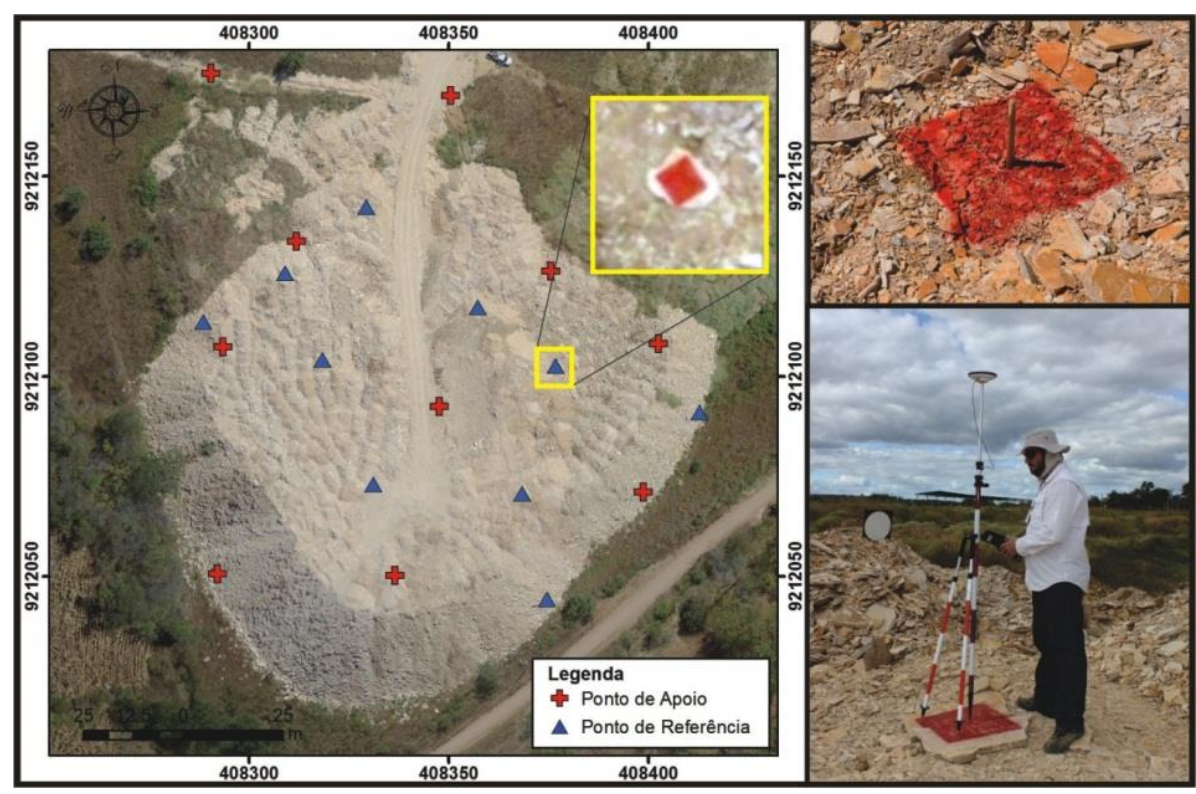

Figura 6: Pontos de apoio e de referência pré-sinalizados e georreferenciados com receptor GNSS geodésico.

\section{Etapa 2: Execução do voo}

Esta etapa inicia com a checagem dos equipamentos em solo, na hipótese de detecção de algum problema, por medida de segurança, a operação é cancelada. Após esta verificação, a decolagem é realizada por meio de lançamento manual e ao atingir a altura de voo estabelecida no planejamento, o piloto automático é acionado, passando a executar o plano de voo elaborado na etapa anterior. Vale salientar que durante esta fase o $\mu$ VANT/DNPM opera de forma automática, mas não autônoma, sendo possível a intervenção do operador a qualquer momento. Toda a operação do $\mu$ VANT/DNPM é controlada pela base de solo, que recebe em tempo real o vídeo da câmera frontal e os dados de telemetria (altitude, velocidade, localização, número de satélites captados pelo GPS e carga da bateria), conforme ilustrado na Figura 7.

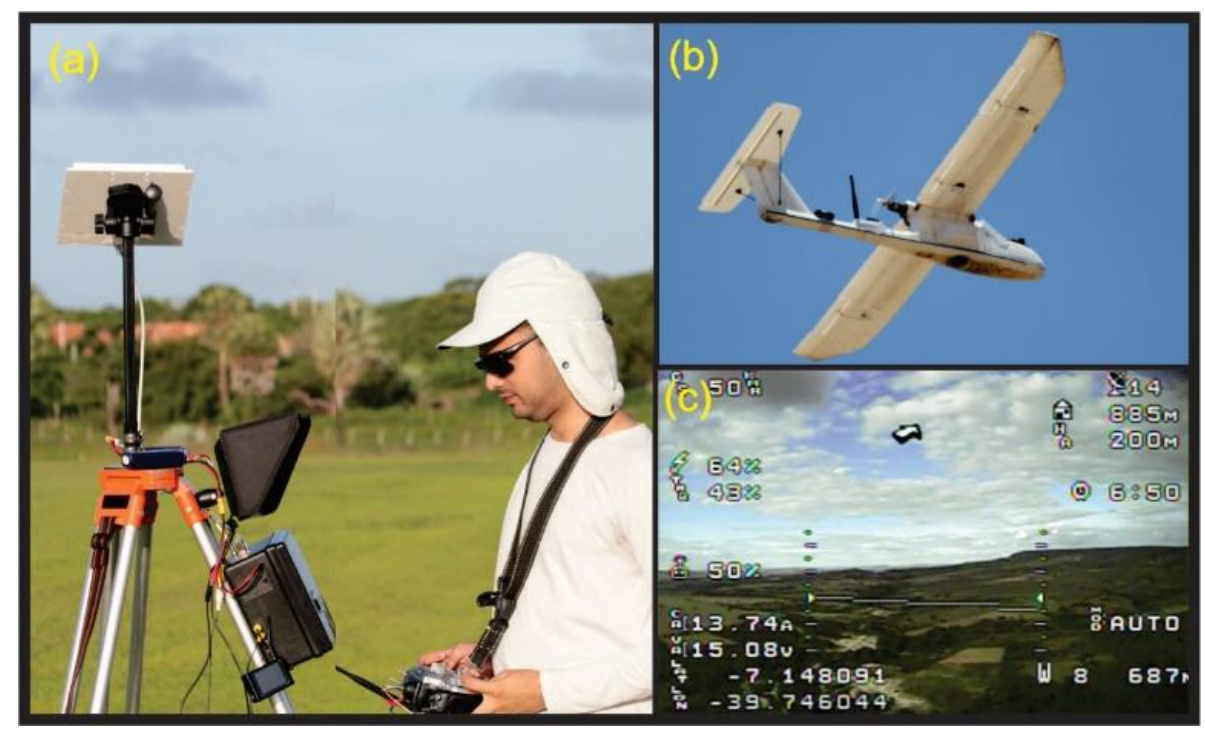

Figura 7: a) base de solo; (b) $\mu$ VANT/DNPM; (c) vídeo recebido na base de solo. 
Após executar o plano de voo a aeronave retorna a base e realiza voo em círculos até que o operador assuma o comando e realize o pouso manualmente. Sendo os resultados do voo realizado para este estudo descritos na Tabela 1.

Tabela 1: Características do voo realizado.

\begin{tabular}{l|c}
\hline \multicolumn{1}{c|}{ Características do Voo } & Valores Observados \\
\hline Altura do voo em relação à base & $100 \mathrm{~m}$ \\
\hline Resolução espacial & $0,02 \mathrm{~m}$ \\
\hline Velocidade média & $60 \mathrm{~km} / \mathrm{h}$ \\
\hline Distância percorrida & $4 \mathrm{~km}$ \\
\hline Número de linhas de voo & 5 \\
\hline Área sobrevoada & $29,7 \mathrm{ha}$ \\
\hline Intervalo de tomada das fotografias & $2 \mathrm{~s}$ \\
\hline Número de fotografias & 177 \\
\hline Recobrimento frontal e lateral & $80 \% \mathrm{e} 60 \%$ \\
\hline
\end{tabular}

\section{Etapa 3: Pós-voo}

Finalizada a etapa de execução do voo é feita uma avaliação dos dados coletados, (fotografias e trilha do GPS), a fim de verificar a qualidade da imagem quanto ao contraste e nitidez. Também é verificada se toda a trilha do voo foi gravada sem interrupções, bem como se durante o voo, devido ao vento, o VANT não se distanciou demasiadamente da linha planejada, causando perda no recobrimento lateral das fotografias. De posse destes dados inicia-se a fase de processamento para geração da nuvem de pontos que será a base para posterior geração do MDT, utilizando o software Agisoft Photoscan versão 1.1.6, solução baseada na tecnologia de reconstrução 3D multiview, que permite processar imagens arbitrárias, sendo eficiente em condições controladas ou não, desde que o objeto a ser reconstruído esteja visível em pelo menos duas imagens distintas.

As três etapas básicas do processamento com o Photoscan, realizadas neste estudo de caso foram: (1) calibração automática da câmera - com base nos dados do EXIF das fotografias; (2) alinhamento das fotos - a partir dos pontos em comum entre as fotografias e pontos de apoio de solo; e (3) geração da nuvem de pontos - com base correlação de imagens, feita por meio de medições de similaridade entre as imagens sobrepostas, são identificadas as coordenadas tridimensionais $(\mathrm{x}, \mathrm{y}, \mathrm{z})$ da superfície fotografada.

\subsection{LiDAR}

De acordo com Santos et al. (2014) a tecnologia Laser Scanner, também conhecida como LiDAR, consiste em um equipamento topográfico capaz de gerar modelos tridimensionais das superfícies de objetos a partir da tecnologia de sensoriamento remoto que mede propriedades da luz refletida por superfícies localizadas à distância do sensor. Podendo ser instalado sobre plataformas terrestres, denominado Laser Scanner Terrestre (LST), ou aéreas, conhecido como Laser Scanner Aerotransportado (LSA).

Neste estudo de caso foi utilizado um LST modelo ILRIS-3D (Intelligent Laser Ranging \& Imaging System), da Optech Inc., empregado com o aparelho montado no tripé, capaz de obter 
até 2.000 pontos por segundo em uma distância de até $2.000 \mathrm{~m}$, gerando uma nuvem de pontos com resolução configurável de até $1,0 \mathrm{~mm}$ no método estático, possibilitando assim, calcular as coordenadas tridimensionais $(\mathrm{x}, \mathrm{y}, \mathrm{z})$ da superfície da pilha de rejeito. Como principais características deste equipamento podem ser destacadas a alta densidade de pontos amostrais coletados com alta precisão e em curto intervalo de tempo (Amaro et al., 2013; Santos et al., 2014).

A coleta dos dados em campo com o LST foi realizada pela equipe do Laboratório de Geoprocessamento (GEOPRO) da Universidade Federal do Rio Grande do Norte (UFRN), sendo necessárias seis varreduras sobre a pilha de rejeito e seu entorno para cobrir toda a superfície. A nuvem de pontos gerada em cada varredura foi georreferenciada com GNSS geodésico para obtenção das coordenadas geodésicas (latitude, longitude e altitude geométrica) a partir de três pontos de controle: a estação base (de instalação do LST) e dois targets posicionados na área de varredura, totalizando 6 bases e 12 targets (Figura 8).

Para pós-processamento dos dados obtidos pelo LST foi utilizando o software PolyWorks versão 12, tendo como saída de dados um conjunto de nuvens dos pontos de reflexão definido pelas coordenadas $\mathrm{x}, \mathrm{y}, \mathrm{z}$, que foi usado para construir o MDT da superfície digitalizada.

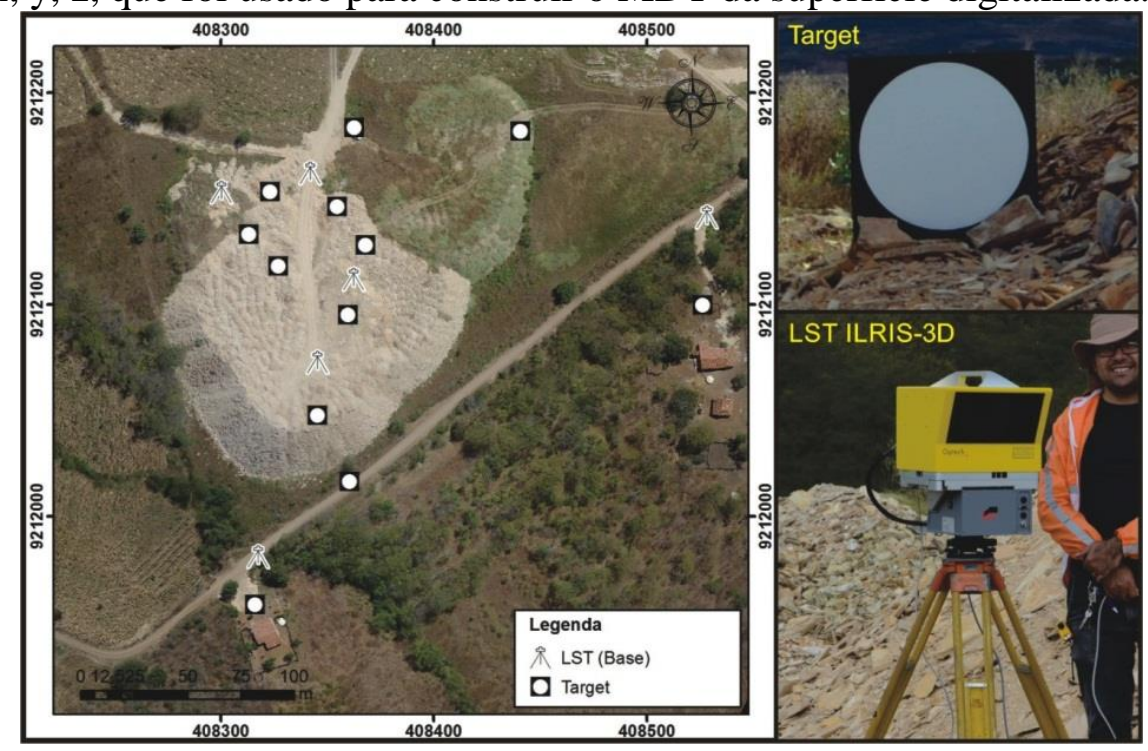

Figura 8: No lado esquerdo, o posicionamento das bases e dos targets no levantamento de campo realizado com LST. No lado direito, em detalhe, o target e o equipamento ILRIS-3D utilizados.

\subsection{Modelo Digital de Terreno (MDT)}

Ao representar a variável altimetria por meio de modelos digitais 3D, construídos com base em nuvens de pontos obtidas pelo método direto, utilizando GNSS geodésico, e indireto, por meio de equipamentos de sensoriamento remoto como varredura LiDAR e fotogrametria digital com VANT (por correlação de imagens), surge a necessidade de distinguir Modelo Digital do Terreno (MDT) de Modelo Digital de Superfície (MDS). De acordo com Baltsavias et al. (1995), MDT corresponde ao modelo do terreno e MDS ao modelo da superfície dos objetos 3D existentes sobre o terreno (vegetação, edificações, etc.). 
Neste estudo de caso foi gerado um MDT a partir de pontos coletados na superfície da pilha de rejeito com GNSS geodésico e da filtragem das nuvens de pontos geradas pelas tecnologias de modelagem da superfície LiDAR e VANT. Sendo eliminados os pontos que não pertenciam à superfície do terreno, assim como os pontos outliers (erros grosseiros com valores muito discrepantes dos demais). Para tanto, foi utilizado o método da filtragem por declividade, onde a declividade e altura são determinadas a partir do vetor que une dois pontos. Caso o ângulo ou altura entre o plano horizontal e o vetor seja maior que o limiar determinado o ponto mais alto é eliminado (Sithole \& Vosselman, 2003).

De posse das nuvens de pontos filtradas, obtidas dos três levantamentos (VANT, GNSS e LiDAR), composta apenas por pontos cotados na superfície da pilha de rejeito, foi criada, no software ArcGIS versão 10.1, uma Triangular Irregular Network (TIN), por triangulação de Delaunay (Amaro et al., 2013) que usa o critério da maximização dos ângulos mínimos de cada triângulo. Nesta estrutura cada ponto da nuvem passou a compor os nós desta malha do tipo vetorial, com topologia do tipo nó-arco, que representa a superfície através de um conjunto de faces triangulares interligadas (Figura 9).
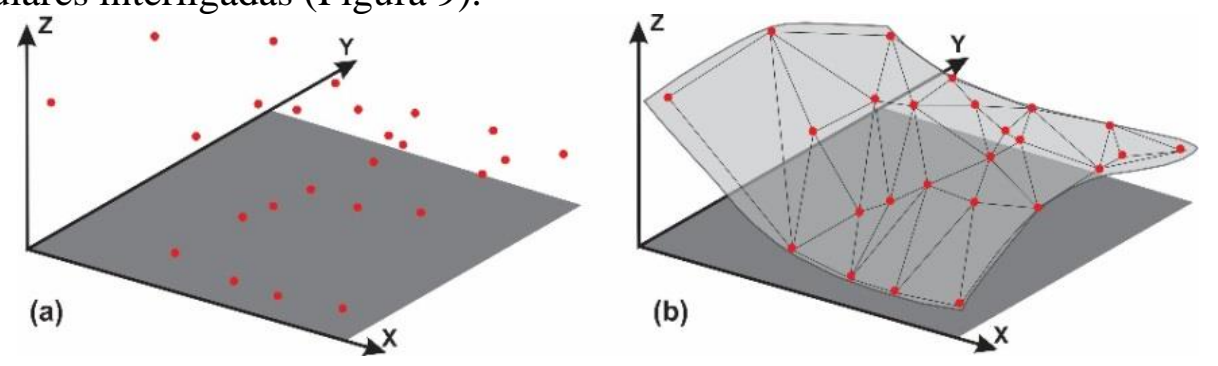

Figura 9: (a) Nuvem de pontos; (b) Superfície de malha triangular derivada da nuvem de pontos. Fonte: Adaptado de Namikawa, (1995 apud Felgueiras in Câmara et al., 2001).

\subsection{Avaliação da Acurácia}

A avaliação da acurácia dos MDTs gerados pelo VANT, GNSS e LiDAR, foi realizada a partir da análise de tendência e precisão dos modelos, sendo os resultados classificados de acordo com o PEC-PCD, conforme tolerâncias estabelecidas pela Diretoria de Serviço Geográfico do Exército Brasileiro - DSG (2011) na Especificação Técnica para a Aquisição de Dados Geoespaciais Vetoriais (ET-ADGV), que estabelece os critérios para que um produto digital possa ser aceito como produto de referência do Sistema Cartográfico Nacional (SCN), e consequentemente para a Infraestrutura Nacional de Dados Espaciais (INDE).

As tolerâncias determinadas pelo PEC-PCD complementam as estabelecidas, para produtos impressos, do Decreto $n^{\circ} 89.817 / 84$. Possuindo tolerâncias específicas para MDTs, sendo o valor previsto para a classe "A" igual a 0,27 da equidistância do produto cartográfico e o erro-padrão (EP) igual a 1/6 da equidistância do produto. As classes "B", "C" e "D" do PEC-PCD correspondem, em ordem, as classes "A", "B", "C" do PEC previstas no Decreto 89.817/84 (Tabela 2). 
Tabela 2: Tolerâncias utilizadas para avaliação da acurácia conforme PEC-PCD (DSG, 2011) e PEC (Decreto-Lei 89.817/84).

\begin{tabular}{c|c|c|c|c|c}
\hline Classe & Classe & \multicolumn{2}{|c|}{ Planimetria } & \multicolumn{2}{c}{ Altimetria } \\
PEC & PEC-PCD & PEC (mm) & EP (mm) & \multicolumn{1}{c}{ PEC (mm) } & EP (mm) \\
\hline- & A & 0,28 & 0,17 & 0,27 & 0,17 \\
\hline A & B & 0,5 & 0,3 & 0,50 & 0,33 \\
\hline B & C & 0,8 & 0,5 & 0,60 & 0,40 \\
\hline C & D & 1,0 & 0,6 & 0,75 & 0,50 \\
\hline
\end{tabular}

A avaliação da acurácia no cálculo do volume da pilha de rejeito objeto deste estudo, a partir dos levantamentos realizados utilizando VANT, GNSS e LiDAR, foi realizada considerando a definição dada por Monico et al. (2009), onde o termo acurácia é relacionado aos efeitos sistemáticos e aleatórios dos erros nas medições, sendo a avaliação dos efeitos de forma independente, a melhor forma de se avaliar a acurácia, possibilitando que haja discriminação entre erros aleatórios e sistemáticos. Para tanto, foi utilizado o método proposto por Galo \& Camargo (1994) de testes de hipóteses, a partir da análise de tendências (baseada na distribuição $t$ de Student, quando é verificada a presença de erros sistemáticos), e precisão (com base na distribuição Qui-quadrado, para avaliação dos efeitos dos erros aleatórios). Ambos os testes realizados com nível de significância de $\alpha=10 \%$. Sendo o modelo considerado acurado para uma determinada classe do PEC-PCD, desde que aceita a hipótese nula da avaliação de tendência e precisão realizada com base nas discrepâncias entre as altitudes observadas no MDT $\left(h_{o}\right)$ e as altitudes de referência $\left(h_{r}\right)$ dos marcos pré-sinalizados em campo e georreferenciados com GNSS geodésico (Equação 1), de onde obtêm-se as estatísticas como média (Equação 2) e desvio padrão (Equação 3), sendo $n$ o número de elementos da amostra.

$$
\begin{aligned}
\Delta h & =\left(h_{0}-h_{r}\right) \\
\overline{\Delta h} & =\frac{1}{n} \sum_{i=1}^{n} \Delta h \\
S_{\Delta h} & =\sqrt{\frac{1}{n-1} \sum_{i=1}^{n}(\Delta h-\overline{\Delta h})^{2}}
\end{aligned}
$$

\section{Análise de tendência}

$\mathrm{Na}$ análise de tendência são avaliadas as hipóteses: $\mathrm{H}_{0}: \mathrm{Se} \overline{\Delta h}=0$, então $h$ não é tendencioso, contra, $\mathrm{H}_{1}: \mathrm{Se} \overline{\Delta h} \neq 0$, então $h$ é tendencioso. A partir do número de pontos de referência utilizados na análise, obtém-se o valor limite tabelado $t_{n-1, \infty / 2}$. Se o valor do teste $t$ de Student calculado (Equação 4) for inferior ao tabelado, atendendo a Equação 5, podemos afirmar que o MDT está livre de erros sistemáticos significativos.

$$
t_{h}=\frac{\overline{\Delta h}}{s_{\Delta h}} \sqrt{n}
$$




$$
\left|t_{c a l c}\right|<t_{n-1, \alpha / 2}
$$

\section{Análise de precisão}

A análise de precisão foi realizada utilizando o teste Qui-quadrado, obedecendo aos valores do EP altimétrico (Tabela 2), estabelecidos na ET-ADGV (DSG, 2011). Para realizar este teste inicialmente calculou-se o erro padrão esperado $\left(\sigma_{h}\right)$, conforme a Equação 6 e posteriormente aplicou-se um teste de hipótese, comparando-se o desvio-padrão das discrepâncias com o EP esperado para a classe do PEC-PCD a qual se deseja testar, $\mathrm{H}_{0}: \mathrm{S}_{\Delta \mathrm{h}}{ }^{2}=\sigma_{\mathrm{h}}{ }^{2}$, contra, $\mathrm{H}_{1}: \mathrm{S}_{\Delta \mathrm{h}}{ }^{2}>\sigma_{\mathrm{h}}{ }^{2}$.

Para atender a precisão de uma determinada classe (A, B, C ou D) o valor do teste Qui-quadrado calculado $\chi_{\mathrm{h}}^{2}$, conforme a Equação 7, deve ser inferior ao teste Qui-quadrado tabelado $\chi_{\mathrm{n}-1, \alpha}^{2}$, de acordo com a Equação 8, permitindo determinar a escala de representação a qual o MDT se enquadra. Onde $n$ é o tamanho da amostra, s o desvio padrão das discrepâncias e $\sigma$ é o EP esperado para uma determinada classe PEC-PCD (Tabela 02).

$$
\begin{gathered}
\sigma_{h}=E P_{A l t} \times E q \cdot \text { dascurvasdenivel } \\
\chi_{h}^{2}=(n-1) \frac{s_{d h}^{2}}{\sigma_{h}^{2}} \\
\chi_{h}^{2} \leq \chi_{(n-1, \alpha)}^{2}
\end{gathered}
$$

\subsection{Cálculo de Volume}

De acordo com Ribeiro Júnior (2011), os modelos digitais gerados a partir dos levantamentos de campo devem ser comparados com a conformação física original do terreno, as chamadas "primitivas", definindo assim os volumes de minério. Na indisponibilidade desta informação, para este estudo de caso decidiu-se gerar um modelo da base da pilha a partir dos pontos rastreados em seu perímetro, levantados com GNSS geodésico no modo cinemático. Sendo este modelo usado como base para o cálculo do volume de todos os modelos testados.

Neste contexto, a cubagem da pilha foi realizada conforme a Equação 9, onde o volume da pilha $\left(V_{p}\right)$ é igual à diferença entre os MDT da pilha $\left(M D T_{p}\right)$ e da encosta $\left(M D T_{e}\right)$, conforme ilustrado na Figura 10.

$$
V_{p}=M D T_{p}-M D T_{e}
$$




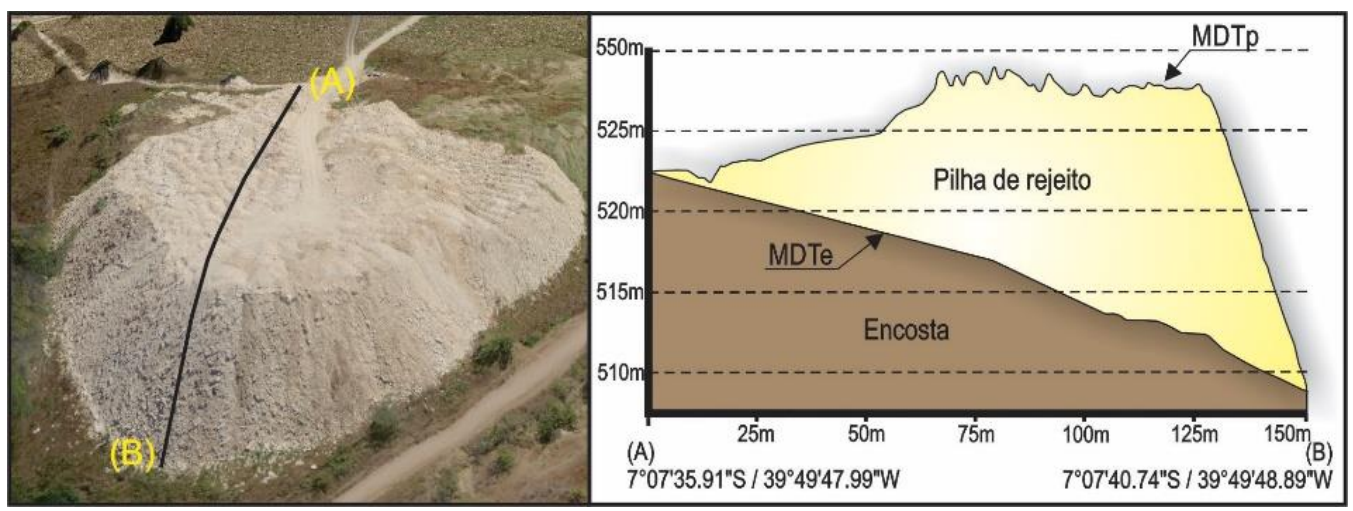

Figura 10: Perfil da disposição da pilha de rejeito sobre a encosta.

\section{Resultados e discussões}

\subsection{MDTs da pilha de rejeito}

De posse das nuvens de pontos obtidas nos levantamentos realizados em campo com GNSS, VANT e LiDAR, foram gerados MDTs com estrutura de malha triangular irregular (TIN), utilizando os próprios pontos amostrados para representar a superfície por meio de uma estrutura formada por triângulos interligados, de forma a representar melhor a superfície não homogênea com variações locais acentuadas da pilha de rejeito objeto deste estudo.

Neste contexto, a varredura com o LiDAR, dentre as ferramentas utilizadas, foi a que gerou a nuvem de pontos mais densa, com mais de 13 milhões de pontos, o que equivale a uma densidade média de 971 pontos $/ \mathrm{m}^{2}$, dando origem a um MDT com quase 27 milhões de triângulos representando a geometria da pilha. Já a nuvem de pontos obtida pelo VANT, por meio da correlação de imagens sobrepostas, obteve uma nuvem de pontos de pouco mais de 2 milhões de pontos, com uma densidade média de 154 pontos $/ \mathrm{m}^{2}$, resultando em um TIN com mais de 4 milhões de faces. Quanto aos resultados obtidos no levantamento com GNSS, por se tratar de um levantamento direto, os resultados alcançados são mais modestos, quando comparados com as outras tecnologias utilizadas neste trabalho, com 5.023 pontos cotados, o que equivale a uma densidade média de apenas 0,36 pontos $/ \mathrm{m}^{2}$, dando origem a uma malha com aproximadamente 9 mil faces (Tabela 3).

Tabela 3: Nuvem de pontos e TIN gerados utilizando VANT, LiDAR e GNSS.

\begin{tabular}{l|c|c|c}
\hline & VANT & LiDAR & GNSS \\
\hline Nuvem de pontos & 2.129 .957 & 13.438 .439 & 5.023 \\
\hline Densidade média da nuvem de pontos (pontos $/ \mathrm{m}^{2}$ ) & 154 & 971 & 0,36 \\
\hline Número de faces dos triangulo (TIN) & 4.246 .537 & 26.875 .007 & 8.999 \\
\hline
\end{tabular}

Para gerar um MDT que represente de maneira coesa a superfície da pilha, as nuvens de pontos obtidas nos três levantamentos realizados, devem ser representativas quanto sua quantidade e posicionamento dos pontos cotados em relação às nuances da superfície irregular da pilha de 
rejeito, sem superamostragem ou escassez de informação. Entretanto, analisando espacialmente a densidade das nuvens de pontos dentro da área de estudo, é possível observar que a varredura com o LiDAR concentrou um número excessivo de pontos próximo à base de onde foi feita a varredura, chegando a uma densidade de até 32.767 pontos $/ \mathrm{m}^{2}$, deixando as áreas mais distantes da base totalmente desprovidas de informação. Já o levantamento com GNSS, apesar de obter densidade máxima de apenas 4 pontos $/ \mathrm{m}^{2}$, com informação concentrada apenas sobre as linhas do caminhamento realizado no modo cinemático, possui pontos cotados bem distribuídos por toda a área da pilha. Quanto ao levantamento utilizando VANT, a nuvem de pontos recobriu toda a área de estudo, apresentando pouca variação de densidade em relação à localização, sendo a porção da nuvem de pontos que representa as áreas com maior declividade mais densa, chegando a 266 pontos $/ \mathrm{m}^{2}$ (Figura 11).

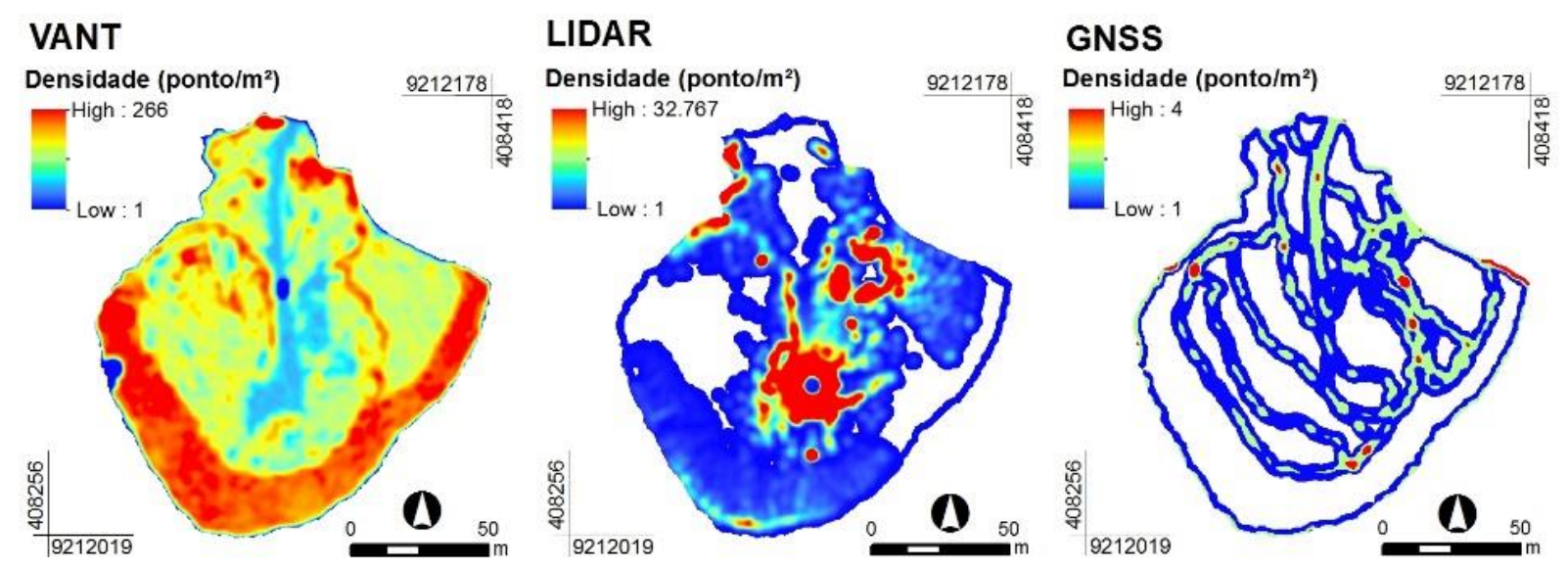

Figura 11: Densidade das nuvens de pontos obtidas pelo VANT, LiDAR e GNSS.

A distribuição irregular da nuvem de pontos refletindo sobre a capacidade do MDT representar de maneira coesa a superfície da pilha de rejeito, fica evidente na análise da Figura 12, onde é possível observar a nuvem de pontos e o MDT representado pelo TIN resultante de cada levantamento, ficando evidente que o modelo gerado a partir da nuvem de pontos do VANT foi o que melhor representou a geometria da pilha, detectando as nuances da superfície irregular da área de estudo.

O MDT gerado a partir dos dados do LiDAR detalhou bem a superfície da pilha somente nas proximidades da base de onde foi realizada a varredura, ao passo que nas áreas com ausência de informação, houve uma simplificação do modelo, assim como ocorreu com a superfície modelada a partir da nuvem de pontos obtida por GNSS, onde houve uma simplificação geral da geometria do topo da pilha. 

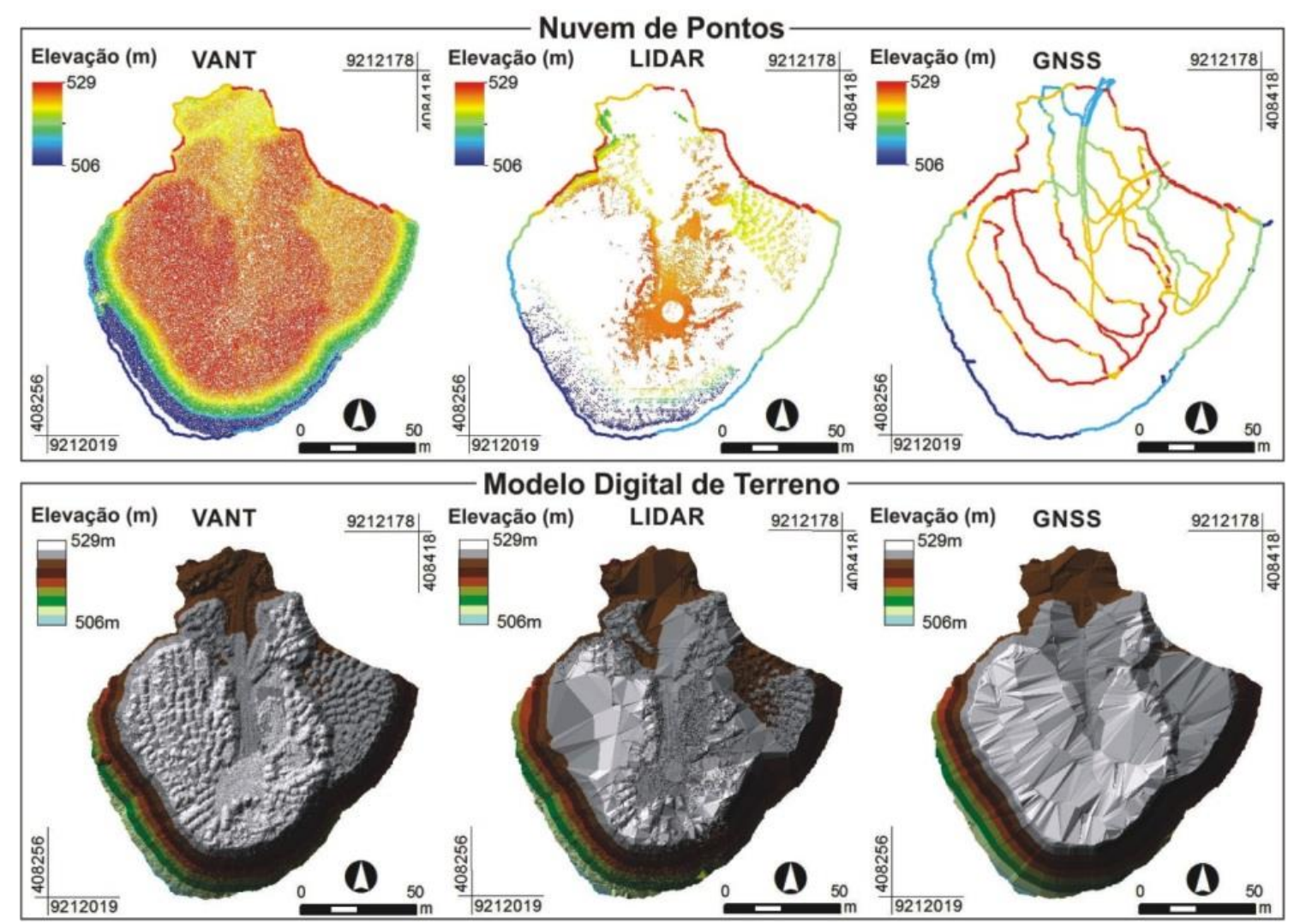

Figura 12: Nuvem de pontos e MDTs gerados pelo método Triangular Irregular Network (TIN).

\subsection{Avaliação da acurácia}

Na avaliação da acurácia dos três modelos (VANT, GNSS e LiDAR), foi realizada a distinção entre os efeitos sistemáticos e aleatórios dos erros nas medições, de modo que o modelo é dito acurado quando é estaticamente preciso e livre de tendências, para uma determinada escala e classe, conforme limites estabelecidos pelo PEC-PCD.

Sendo assim, inicialmente foram calculadas as discrepâncias entre as altimetrias observadas nos MDTs e as cotas dos 10 pontos de referência, obtidas em campo com GNSS geodésico (Equação 1), bem como sua média e desvio padrão (Equações 2 e 3), sendo o resultado apresentado na Tabela 4. Enquanto na Figura 13 são apresentados na forma de gráfico os valores das discrepâncias descritos nesta tabela, sendo possível visualizar a origem dos valores obtidos pelo desvio padrão, que indica a dispersão das discrepâncias em função de sua média, sendo este reflexo da distribuição da informação na nuvem de pontos resultante das três tecnologias, onde a nuvem de pontos gerada pelo VANT, bem distribuída sobre toda a superfície da pilha, apresentou uma pequena dispersão dos valores das discrepâncias em relação aos pontos de referência, enquanto as modelagens realizadas a partir dos dados GNSS e principalmente do LiDAR, obtiveram maior dispersão, devido à falta de informação em algumas áreas da nuvem de pontos, onde não foi possível modelar de forma coerente à superfície do local. 
Tabela 4: Estatísticas das discrepâncias.

\begin{tabular}{|c|c|c|c|c|c|c|c|}
\hline Ponto & $\begin{array}{c}\mathrm{h}_{\mathrm{o}} \\
\text { VANT }\end{array}$ & $\begin{array}{c}\mathrm{h}_{\mathrm{o}} \\
\text { GNSS }\end{array}$ & $\begin{array}{c}\mathrm{h}_{\mathrm{o}} \\
\text { LiDAR }\end{array}$ & $\mathrm{h}_{\mathrm{r}}$ & VANT & $\begin{array}{c}\Delta \mathrm{h} \\
\text { GNSS }\end{array}$ & LiDAR \\
\hline 1 & 524,863 & 524,893 & 524,992 & 524,870 & $-0,007$ & 0,023 & 0,122 \\
\hline 2 & 527,325 & 527,701 & 527,472 & 527,334 & $-0,009$ & 0,367 & 0,138 \\
\hline 3 & 524,969 & 525,160 & 525,210 & 524,934 & 0,035 & 0,226 & 0,276 \\
\hline 4 & 528,918 & 528,890 & 528,830 & 528,883 & 0,035 & 0,007 & $-0,053$ \\
\hline 5 & 528,833 & 528,504 & 529,021 & 528,969 & $-0,136$ & $-0,465$ & 0,052 \\
\hline 6 & 529,113 & 529,174 & 529,142 & 529,070 & 0,043 & 0,104 & 0,072 \\
\hline 7 & 516,296 & 516,216 & 517,020 & 516,210 & 0,086 & 0,006 & 0,810 \\
\hline 8 & 523,510 & 523,488 & 523,544 & 523,527 & $-0,017$ & $-0,039$ & 0,017 \\
\hline 9 & 526,855 & 526,902 & 526,865 & 526,899 & $-0,044$ & 0,003 & $-0,034$ \\
\hline 10 & 517,412 & 517,439 & 517,216 & 517,437 & $-0,025$ & 0,002 & $-0,221$ \\
\hline \multicolumn{5}{|c|}{ Média $\overline{\Delta h}$} & $-0,004$ & 0,023 & 0,118 \\
\hline \multicolumn{5}{|c|}{ Desvio Padrão $S_{\Delta h}$} & 0,060 & 0,213 & 0,277 \\
\hline
\end{tabular}

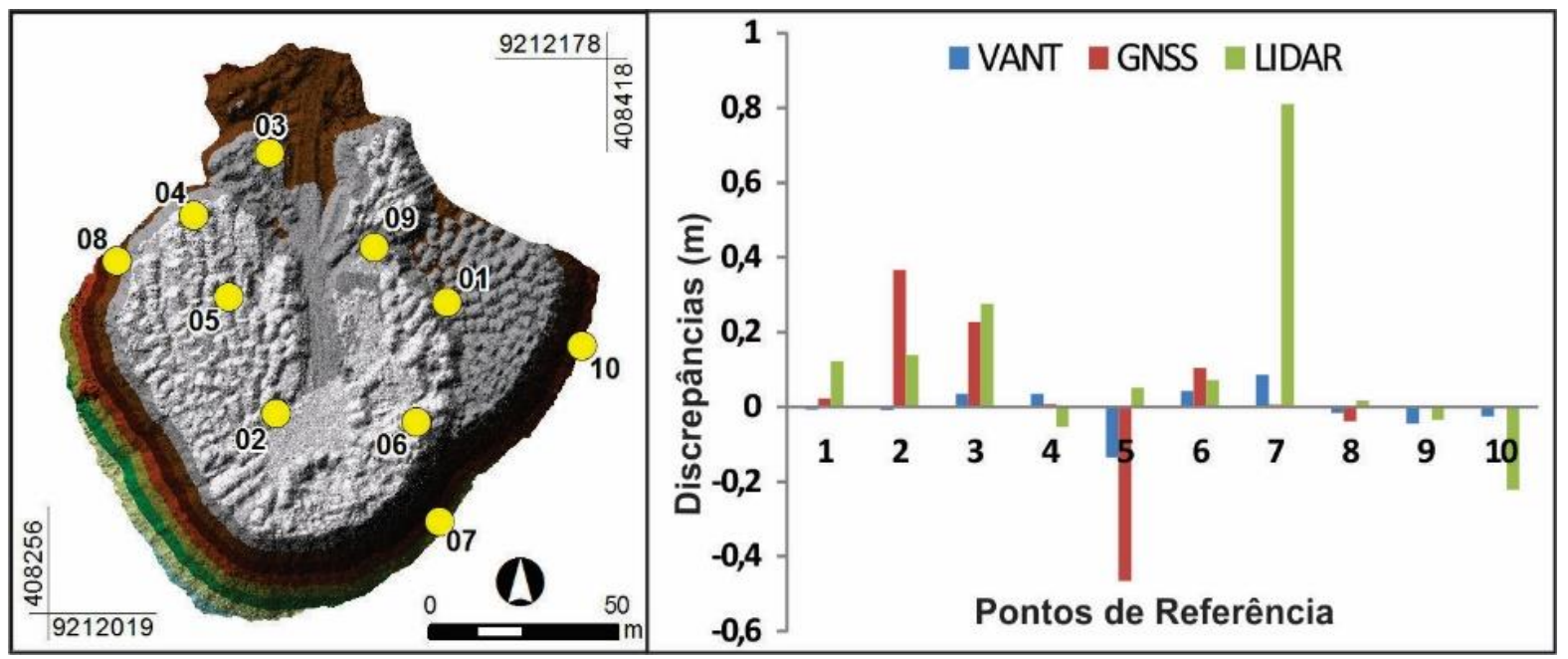

Figura 13: Gráfico das discrepâncias.

$\mathrm{Na}$ análise de tendência verificou-se se que o valores do $t$ amostral calculado (Equação 4) para os três modelos analisados estavam no intervalo de aceitação da Equação 5, dado pelo valor tabelado de $t$ de Student para um nível de confiança $(1-\alpha)$ igual a $90 \%(\alpha=0,10)$, que neste estudo de caso, considerando os 10 pontos de referência utilizados na análise obtém-se o valor limite de $t_{10(9)}$ igual a 1,383 indicando que os três modelos testados estão livres de tendência (Tabela 5).

No tocante a precisão, os MDTs gerados a partir dos dados obtidos pelo VANT, GNSS e LiDAR, obtiveram precisão compatível com a Classe A do PEC-PCD para equidistância vertical de $0,3 \mathrm{~m}, 1,0 \mathrm{~m}$ e 1,3 m respectivamente. Para tanto foi considerando o erro padrão esperado $(\sigma)$ de 1/6 da equidistância vertical avaliada, limite tabelado de $\chi^{2}$ de 14,684 considerando uma amostra $(n)$ de tamanho 10, nível de significância de 10\% e 9 graus de liberdade (Tabela 5). 
Tabela 5: Avaliação da acurácia.

\begin{tabular}{c|c|c|c}
\hline & VANT & GNSS & LiDAR \\
\hline$\overline{\Delta h}$ & $-0,004$ & 0,023 & 0,118 \\
\hline$S$ & 0,060 & 0,213 & 0,277 \\
\hline$n$ & 10 & 10 & 10 \\
\hline$\sigma$ & 0,051 & 0,170 & 0,221 \\
\hline$t_{10 \%(9)}$ & 1,383 & 1,383 & 1,383 \\
\hline$\left|t_{\text {calc }}\right|$ & 0,206 & 0,347 & 1,349 \\
\hline$\chi_{10 \%(9)}^{2}(14,684$ & 14,684 & 14,684 \\
\hline$\chi^{2}$ Calculado & 12,614 & 14,169 & 14,106 \\
\hline Classe & Classe A & Classe A & Classe A \\
PEC-PCD & Eq. vertical: $0,3 \mathrm{~m}$ & Eq. vertical: $1,0 \mathrm{~m}$ & Eq. vertical: $1,3 \mathrm{~m}$ \\
\hline
\end{tabular}

\subsection{Cálculo de Volume}

O volume da pilha, objeto deste estudo, foi calculado pela diferença entre os MDTs modelados (VANT, GNSS e LiDAR) e o MDT da encosta em que o rejeito foi depositado (Equação 9), conforme resultados expressos na Tabela 6 , onde pode ser constatado que os volumes calculados possuem uma relação inversa com a acurácia da modelagem, onde quanto menor a acurácia do MDT, maior o volume mensurado. A explicação deste fato está na simplificação do modelo causada pela ausência de informação em algumas áreas da superfície da pilha, como pode ser observado na Figura 14, onde a partir de um perfil traçado sobre as nuvens de pontos geradas pelas três tecnologias avaliadas, em umas das áreas mais irregulares do topo da pilha, é possível observar que a nuvem de pontos obtida pelo VANT não apresenta falhas, possuindo pontos cotados sobre toda a superfície da pilha cortada pelo perfil, enquanto a nuvem gerada pelo LiDAR, e principalmente pelo GNSS, possuem vários gaps de informação.

A incapacidade de modelar todas às nuances da superfície irregular da pilha de rejeito, no caso do GNSS, se deve ao fato de que os pontos cotados foram rastreados apenas no caminhamento cinemático realizado entre os pequenos amontoados de material, enquanto na modelagem realizada com o LiDAR, estes amontoados funcionaram como barreiras a varredura laser, fazendo com que o equipamento conseguisse varrer apenas as faces voltadas para o sensor, sendo a superfície modelada a ligação entre os pontos cotados em cada levantamento, que no MDT gerado pelo LiDAR, foi a ligação entre os topos dos amontoados, o que ocasionou a cubagem das áreas localizadas entre estas irregularidade da superfície da pilha, como ilustrado na Figura 15 que apresenta de forma esquemática o resultado obtido pelas três tecnologias.

Tabela 6: Volume calculado da pilha.

\begin{tabular}{c|c|c}
\hline MDT & Volume $\left.\mathbf{( m}^{3}\right)$ & $\begin{array}{c}\text { Acurácia } \\
\text { (PEC-PCD Classe } \text { A) }\end{array}$ \\
\hline VANT & $108.106,989$ & $0,3 \mathrm{~m}$ \\
\hline GNSS & $109.952,258$ & $1,0 \mathrm{~m}$ \\
\hline LiDAR & $111.629,986$ & $1,3 \mathrm{~m}$ \\
\hline
\end{tabular}




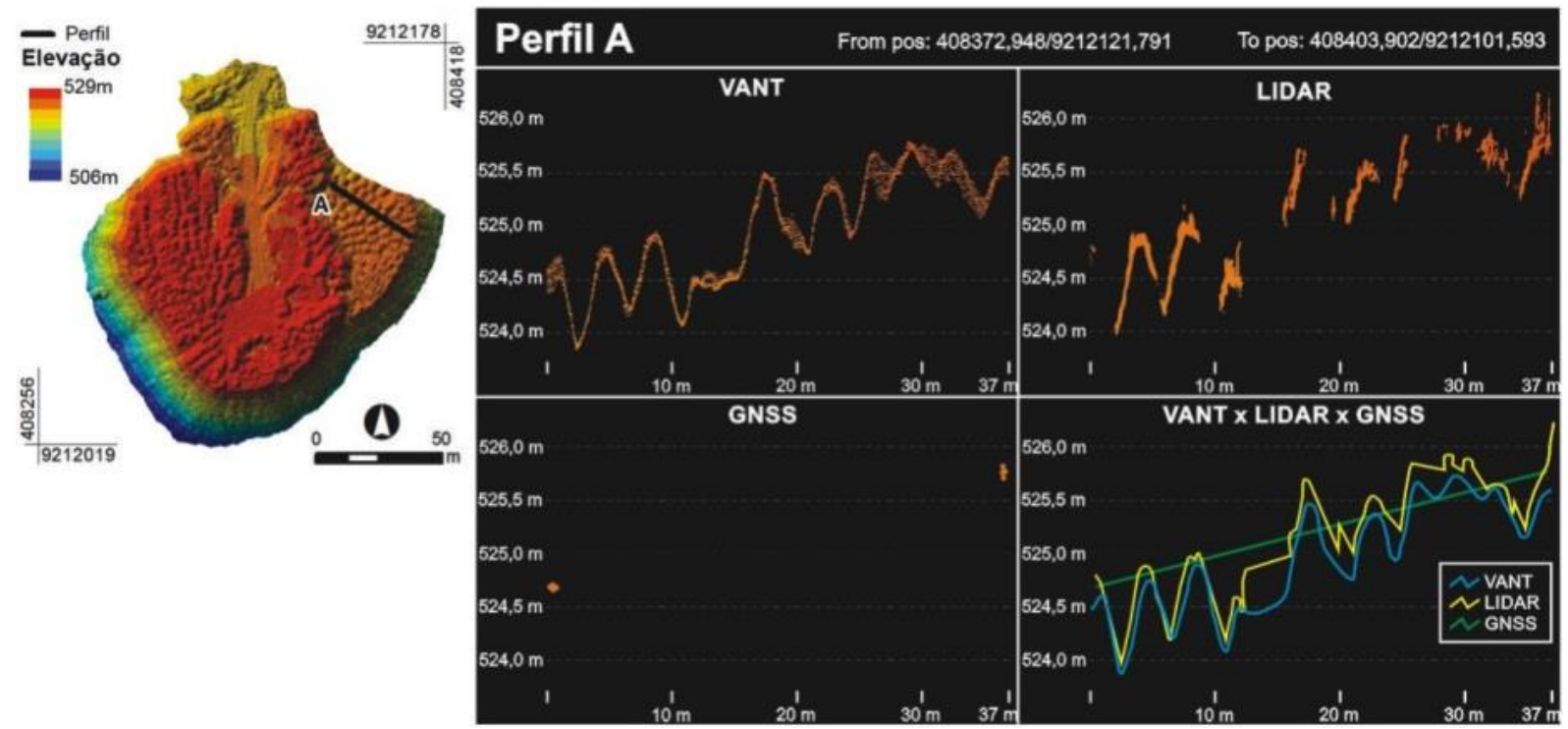

Figura 14: Perfil traçado sobre as nuvens de pontos geradas pelo VANT, LiDAR e GNSS.

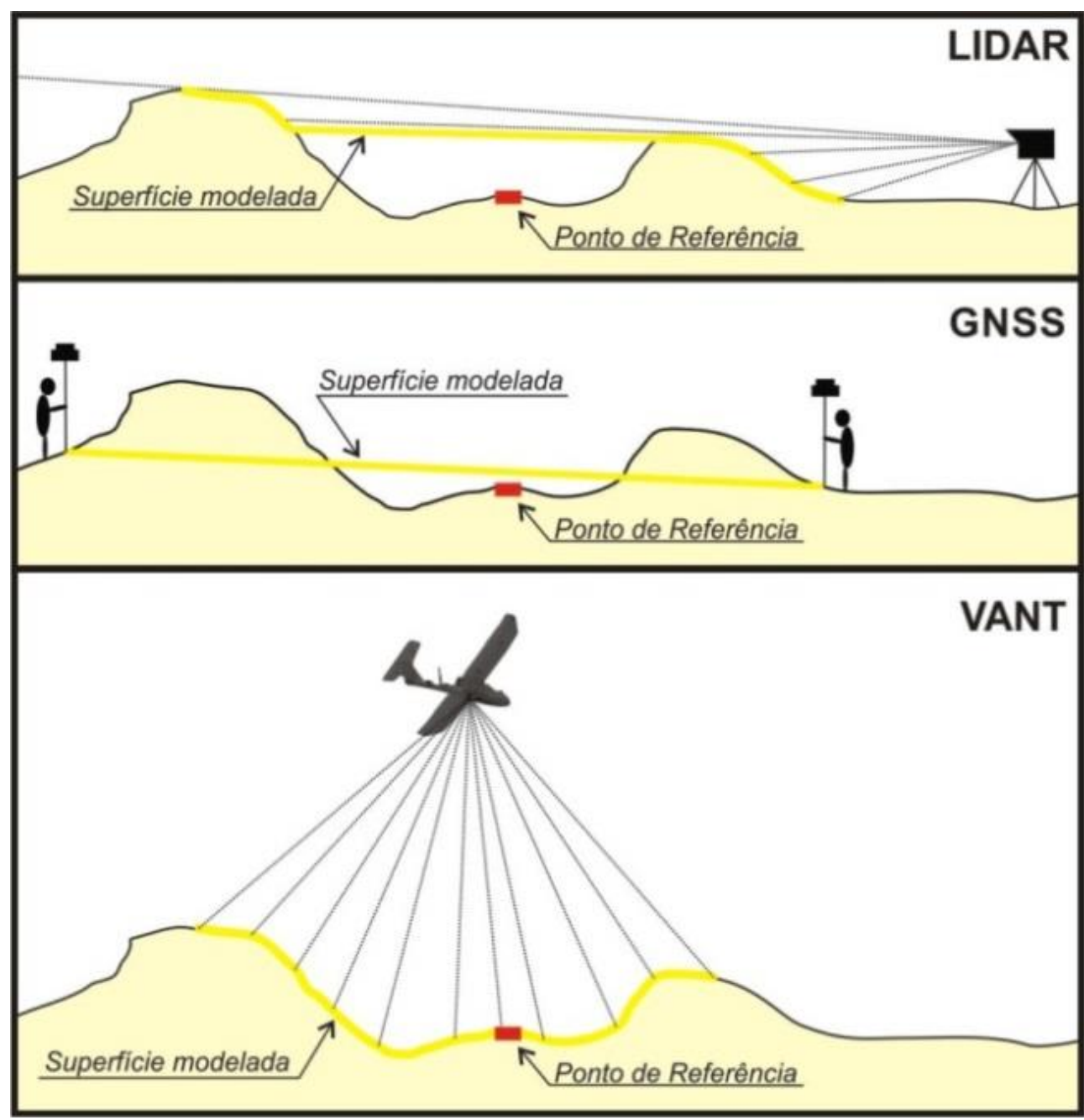

Figura 15: Representação esquemática dos MDTs do VANT, LiDAR e GNSS. 


\section{Conclusões}

A partir dos resultados obtidos neste trabalho é possível concluir que o VANT apresentou a melhor acurácia no cálculo do volume da pilha de rejeito avaliada, seguido pela modelagem obtida pelo levantamento GNSS e LiDAR respectivamente, permitindo a obtenção de informações topográficas tridimensionais da superfície da pilha, inclusive em regiões inacessíveis as outras duas ferramentas avaliadas, com precisão, e elevado grau de detalhamento. $\mathrm{O}$ melhor resultado obtido pelo VANT é atribuído principalmente à perspectiva aérea e nadir do levantamento, que permitiu gerar uma nuvem de pontos bem distribuída sobre toda a área de estudo, inclusive entre os pequenos amontoados de material existentes no topo da pilha.

Entretanto, vale salientar que este resultado não significa que o VANT é uma ferramenta mais precisa que o GNSS ou LiDAR, mas sim que o VANT foi a melhor solução para o problema proposto, considerando que foram aplicadas metodologias de levantamento de campo que permitissem o melhor resultado no menor espaço de tempo, não sendo possível, por exemplo, realizar um maior número de varreduras com o LiDAR ou um maior caminhamento cinemático com o GNSS, uma vez que a mineração estava em plena atividade.

Diante dos bons resultados apresentados no levantamento com o VANT, podemos concluir que o cálculo de volume utilizando MDT gerado por fotogrametria digital, utilizando uma câmera de pequeno formato, pelo método de computação de similaridades entre imagens sobrepostas devidamente orientadas, é um produto com precisão e confiabilidade compatível com as tecnologias de levantamento altimétrico mais utilizadas para esta finalidade, à varredura LiDAR e o método de levantamento cinemático com GNSS, com a vantagem de possuir características como elevada produtividade, necessidade de pouca mão de obra, baixo custo do equipamento, elevada segurança, uma vez que não existe contato direto entre o operador do VANT e a pilha de rejeito modelada, e alta acurácia no cálculo do volume.

Tal conclusão pode ser constatada na Tabela 7, onde é apresentado um comparativo do desempenho obtido pelas três tecnologias avaliadas para solucionar o problema proposto, considerando os quesitos: (1) tempo de levantamento; (2) tempo de pós-processamento; (3) número de pessoas envolvidas; (4) custo do equipamento; (5) segurança; e (6) acurácia. Onde a - indica um alto desempenho em relação às demais tecnologias avaliadas; o desempenho semelhante ao melhor resultado observado dentre os três; e baixo desempenho quando comparado com o resultado obtido pelas outras ferramentas.

Como é possível observar na Tabela 7, o LiDAR terrestre apresentou o pior desempenho deste comparativo, sendo a ferramenta de valor mais elevado, demandando o maior tempo para realizar o trabalho, gerando uma grande quantidade de informação que demandou muitas horas de pós-processamento, além de envolver um maior número de pessoas na operação, com risco moderado, uma vez que mesmo se tratando de um equipamento de sensoriamento remoto, onde não é necessário o contato direto com a superfície modelada, foi preciso subir na pilha para posicionar os targets utilizados para georreferenciar o levantamento. Quanto a acuraria no cálculo do volume, o LiDAR teve seu desempenho prejudicado pela impossibilidade de realizar um maior número de varreduras e devido à irregularidade da superfície da pilha, que funcionou como barreira para a varredura laser, causando uma superamostragem da nuvem de pontos próximo ao local onde foram realizadas as varreduras, e ausência de informação a jusante dos pequenos amontoados existentes no topo da pilha.

Já o GNSS, apesar da limitação para gerar uma nuvem de pontos que contemplasse todas as nuances da superfície da pilha, apresentou um resultado considerado satisfatório, mostrando-se uma alternativa para cálculos menos acurados, apresentando como vantagens o custo do equipamento, menor número de pessoas necessárias para operá-lo, e maior agilidade no pós-

Bol. Ciênc. Geod., sec. Artigos, Curitiba, v. 22, nำ1, p.73 -94, jan-mar, 2016. 
processamento dos dados. Entretanto, esta ferramenta mostrou-se desfavorável nos quesitos tempo de levantamento, acurácia, e principalmente segurança, por se tratar de um levantamento direto, que exige que operador percorra toda a superfície da pilha, deixando-o susceptível a acidentes causados pela instabilidade do material.

Diante do exposto, espera-se que este trabalho tenha elucidado as dúvidas quanto à acurácia e aplicação do VANT, GNSS e LiDAR no cálculo do volume de pilhas de rejeito, por meio das potencialidades e restrições do uso destas ferramentas apresentadas neste trabalho.

Tabela 7: Comparativo do desempenho das modelagens realizadas com VANT, GNSS e LiDAR.

\begin{tabular}{|c|c|c|c|c|c|}
\hline & VANT & \multicolumn{2}{|l|}{ GNSS } & \multicolumn{2}{|l|}{ LiDAR } \\
\hline Tempo de levantamento & $10 \mathrm{~min}$. & 8 horas & 8 & 12 horas & 8 \\
\hline Tempo de pós-processamento & 8 horas & 1 hora & 순 & 48 horas & 8 \\
\hline $\mathrm{N}^{0}$ de pessoas envolvidas & 2 pessoas & 1 pessoa & 4 & 3 pessoas & 8 \\
\hline Custo do equipamento & $\mathrm{R} \$ 55 \mathrm{mil}$ & $\mathrm{R} \$ 75 \mathrm{mil}$ & 0 & $\mathrm{R} \$ 800 \mathrm{mil}$ & 8 \\
\hline Segurança & Alta 1 & Baixa & 8 & Moderada & 0 \\
\hline Acurácia & $0,3 \mathrm{~m}$ & $1,0 \mathrm{~m}$ & 8 & $1,3 \mathrm{~m}$ & 8 \\
\hline
\end{tabular}

\section{REFERÊNCIAS BIBLIOGRÁFICAS}

Amaro, V. E.; Lima, F. G. F., Santos M. S. T. "An Evaluation of Digital Elevation Models to Short-Term Monitoring of a High Energy Barrier Island, Northeast Brazil." International Scholarly and Scientific Research \& Innovation, Vol:7, No:4, (2013): 132-139.

Amaro, V. E.; Santos, A. L. S.; Scudelari, A. C.; Costa, B. C. P. "Use of terrestrial LiDAR for quantifying morphological changes in Ponta Negra Beach, Natal City, Northeast Brazil." Paper presented at the CoastGIS 2013 Conference: Monitoring and Adapting to Change on the Coast, Victoria, BC, Canada, 2013, v. 1. p. 5-9.

Baltsavias, E.; Mason, S.; Stallmann, D. "Use of DTMs/DSMs and orthoimages to support building extraction. In Automatic Extraction of Man-Made Objects from Aerial Space Images, edited by A. Gruen, O. Kuebler \& P. Agouris, 199-210. Basel: Birkhauser Verlag, 1995.

Câmara, G.; Davis, C.; Monteiro, A. M. V. Introdução à Ciência da Geoinformação. São José dos Campos, INPE, 2001.

Diretoria de Serviço Geográfico (DSG). Especificação técnica para a aquisição de dados geoespaciais vetoriais (ET- ADGV). Ministério da Defesa, Exército Brasileiro, Departamento de Ciência e Tecnologia. Brasília - DF, $2^{\text {a }}$ edição, 2011.

Galo, M.; Camargo, P. O. "Utilização do GPS no controle de qualidade de cartas." Artigo apresentado no $1^{\circ}$ Congresso Brasileiro de Cadastro Técnico Multifinalitário, Florianópolis Brasil, Tomo II, 1994, 41-48.

Instituto Brasileiro de Geografia e Estatística (IBGE). Recomendações para levantamentos relativos estáticos - GPS. Brasília, 2008. Acessado em 26 de agosto de 2014. ftp://geoftp.ibge.gov.br/documentos/geodesia/pdf/recom_gps_internet.pdf.

Menezes, R. R.; Melo, L. R. L.; Fonsêca, F. A. S.; Souto, P. M.; Neves, G. A.; Santana, L. N. L. "Reciclagem do resíduo da serragem de calcário laminado para produção de blocos cerâmicos." REM: R. Esc. Minas, Ouro Preto, 63(4): 667-672, out./dez. 2010. 
Monico, J. F. G.; Póz, A. P. D.; Galo, M.; Santos, M. C.; Oliveira, L. C. "Acurácia e precisão: revendo os conceitos de forma acurada." Bol. Ciênc. Geod., sec. Comunicações, Curitiba, v. 15, $\mathrm{n}^{\circ} 3$, p.469-483, jul-set, 2009.

Moura, W. A.; Leite M. B.; Bastos, A. J. O. "Avaliação do uso de resíduo de serragem de pedra Cariri (RSPC) para produção de concretos convencionais." Ambiente Construído, Porto Alegre, v. 13, n. 1, p. 7-24, jan./mar. 2013.

Perdigão, T. D.; Santos, A. P. "Avaliação da acurácia a partir de diferentes tempos de rastreio utilizando a solução PPP on-line do IBGE.” Artigo apresentado no III Simpósio Brasileiro de Ciências Geodésicas e Tecnologias da Geoinformação. Recife - PE, 2010. p. 001 - 007.

Ribeiro Júnior, S. 2011. "Determinação de volumes em atividades de mineração utilizando ferramentas do sensoriamento remoto.” Tese (Doutorado) Universidade Federal de Viçosa. PósGraduação em Engenharia Civil. Viçosa.

Santos, A. L. S.; Amaro, V. E.; Santos, M. S. T. "Terrestrial laser scanner applied to monitoring beach morphological changes in a high energy coastal zone in northeast Brazil." Paper presented at the 7th International Terrestrial Laser Scanning User Meeting, 2014, Rome-Italy. International Terrestrial Laser Scanning User Meeting, 2014. v. 1. p. 1-13, 2014.

Santos, M. S. T.; Amaro, V. E.; Souto, M. V. S. "Metodologia geodésica para levantamento de Linha de Costa e Modelagem Digital de Elevação de praias arenosas em estudos de precisão de geomorfologia e dinâmica costeira." Revista Brasileira de Cartografia (Impresso), v. 63, p. 663 681, 2011.

Silva, A. D. A. 2008. "Aproveitamento de rejeito de calcário do Cariri Cearense na formulação de argamassa.” Dissertação (Mestrado) - Universidade Federal de Pernambuco. CTG. Programa de Pós-Graduação em Engenharia Mineral, Recife.

Silva, C. A; Duarte, C. R.; Souto, M. V. S. Sabadia, J. A. B. "Utilização de VANT para geração de ortomosaicos e aplicação do Padrão de Exatidão Cartográfica (PEC)". Artigo apresentado no SIMPÓSIO BRASILEIRO DE SENSORIAMENTO REMOTO (SBSR), 2015, João Pessoa. Anais... João Pessoa: INPE, 2015.

Sithole, G.; Vosselman, G. "Comparison of Filter Algorithms." International Archives of Photogrammetry, Remote Sensing and Spatial Informatin Sciences. Vol. 34, Part 3/W13, pp. 7178, 2003.

Vidal, F. W. H.; Castro, N. F. Arranjo produtivo local (APL) de base mineral dos calcários do Cariri $-C E$. Relatório técnico final de atividades realizadas (2005-2009). Centro de Tecnologia Mineral - CETEM, 2009.

Vidal, F. W. H.; Padilha, M. W. M.; Oliveira, R. R. "Aspectos geológicos da Bacia do Araripe e do aproveitamento dos rejeitos da Pedra Cariri - Ceará.” Artigo apresentado no V Simpósio de Rochas Ornamentais do Nordeste, Recife, 2005. p. 31-36.

Recebido em fevereiro de 2015.

Aceito em setembro de 2015. 